\title{
Life-threatening air embolism during ERCP
}

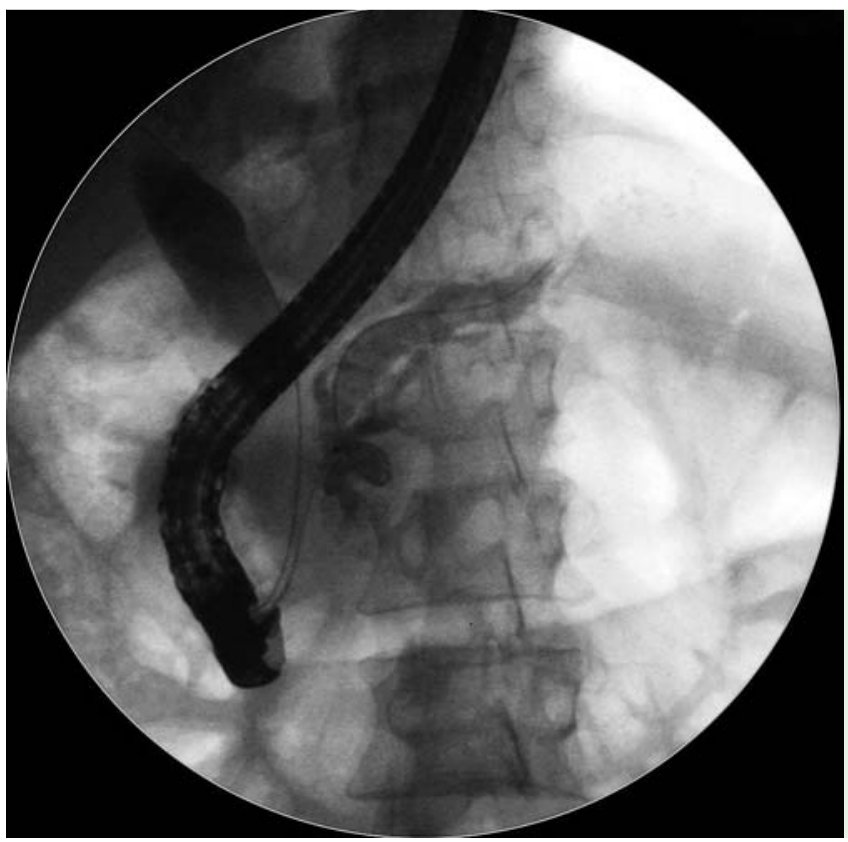

Fig. 1 Endoscopic retrograde cholangiopancreatography (ERCP) showing double duct dilatation in patient \#1.

Patient \#1, a 45-year-old man who was being monitored because of chronic pancreatitis, had anicteric cholestasis and pain caused by double-duct stricture. Endoscopic retrograde cholangiopancreatography (ERCP) was undertaken using air, with the patient under general anesthesia with intubation ( Fig.1). After short sphincterotomies had been done, self-expanding metal stents were inserted ( $10 \mathrm{~mm}$ diameter for the common bile duct [CBD], and $6 \mathrm{~mm}$ diameter for the pancreatic duct, both $60 \mathrm{~mm}$ length;). At 1 hour after the procedure was started, the patient became hypocapnic. An inferolateral ST segment elevation mandated coronary angiography. Gas bubbles were visualized in the heart cavities ( $\bullet$ Fig. 2), and echocardiography showed a patent foramen ovale. Administration of pure oxygen and aspiration of bubbles improved the patient's hemodynamic status. Brain magnetic resonance imaging revealed ischemic lesions. The patient was transferred quickly for initiation of hyperbaric oxygen therapy (HBOT). He was referred, 1 month later, to a rehabilitation unit because of nonregressing tetraparesis.
Patient \#2 was an 87-year-old man was scheduled for ERCP to remove a $15-\mathrm{mm}$ gallstone from the CBD. ERCP was undertaken using air, with the patient under general anesthesia with intubation. Although a long biliary sphincterotomy was made, extraction of the gallstone was unsuccessful. A 45-mm 10-Fr Teflon-coated stent was inserted. At 1 hour after the start of ERCP, the patient was seen to be having a cardiac arrest. After resuscitation procedures had been carried out, echocardiography visualized air in the heart cavities; the foramen ovale was not patent. The patient was transferred for initiation of HBOT. He returned home, without sequelae, on day 16 .

Air embolism is a complication of ERCP that has a mortality of $40 \%$. Echocardiography is the diagnostic exploration of choice and can also determine whether the foramen ovale is patent; this condition can lead to paradoxical embolism. A whole-body tomography determines the extent of the lesions.

Oxygen is the specific treatment for air embolism, and should be started without delay, to reduce the bubble size. HBOT maintains oxygen supply to ischemic tissues while reducing the intracranial

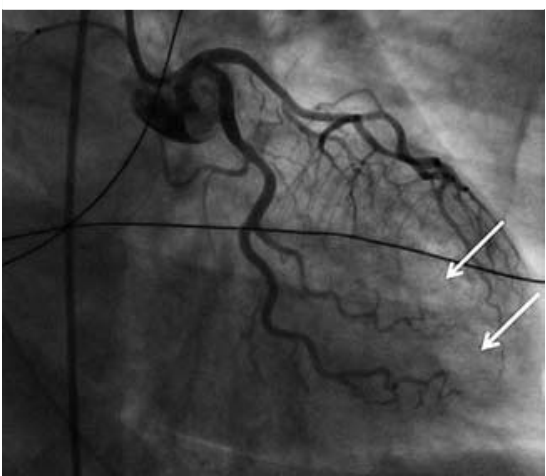

Fig. 2 Coronary angiography in patient \#1, showing gas bubbles (arrows) in the heart cavities.

hypertension, and the most favorable neurological results are obtained when HBOT is initiated quickly [1]. The patient's survival and functional prognosis depend directly on rapid diagnosis and treatment.

Endoscopy_UCTN_Code_CPL_1AK_2AC

Competing interests: None

Clotilde Duburque ${ }^{1,2,3,4}$, Erick

Beaujard5 $^{5}$, Jean-Baptiste Landel', 2,3,6, Riadh Rihani ${ }^{1,2,3,6}$, Karim Merouani ${ }^{7}$, Wissam Yassine ${ }^{1,2,3,4}$, Olivier Lucidarme $^{8}$, Damien Lucidarme ${ }^{1,2,3,4}$

${ }^{1}$ Université Nord de France, Lille, France

2 UCLille, Lille, France

${ }^{3}$ Groupement des Hôpitaux de l'Institut Catholique de Lille/Faculté Libre de Médecine, Lille, France

${ }^{4}$ Département Médico-Chirurgical d'Hépato-Gastroentérologie, Centre Hospitalier Saint-Philibert, Lomme-lèsLille, France

${ }^{5}$ Service de Gastro-Entérologie, Centre Hospitalier Intercommunal Alençon Mamers, Alençon, France

${ }^{6}$ Département de Cardiologie, Centre Hospitalier Saint-Philibert, Lomme-lèsLille, France

${ }^{7}$ Service de Réanimation, Centre Hospitalier Intercommunal Alençon Mamers, Alençon, France

${ }^{8}$ Service de Réanimation, Centre Hospitalier d'Avranches, France 


\section{Reference}

1 Raju GS, Bendixen BH, Khan J et al. Cerebrovascular accident during endoscopy: consider cerebral air embolism, a rapidly reversible event with hyperbaric oxygen therapy. Gastrointest Endosc 1998; 47: 70-73
Bibliography

Dol http://dx.doi.org/

10.1055/s-0034-1365098

Endoscopy 2014; 46: E250-E251

(c) Georg Thieme Verlag KG

Stuttgart · New York

ISSN 0013-726X
Corresponding author

Dr. C. Duburque

Pathologies digestives,

Université Catholique de Lille

115 rue du grand but

59462 Lomme Cedex, BP 249

France

Fax: +0320005611

Duburque.Clotilde@ghicl.net 